\title{
Geospatial Mapping of Health Facilities in Yola, Nigeria
}

\author{
Abubakar Sadiq Bukhari, Ibrahim Muhammed \\ Department of Surveying and Geo-informatics, School of Environmental Sciences, \\ Modibbo Adama University of Technology, PMB 2076 Yola, Adamawa State, Nigeria.
}

\begin{abstract}
This paper investigates the spatial distribution of health facilities and their attribute information by creating a database and producing a visual map of these facilities in Yola town. Twelve facilities were mapped consisting of hospitals, clinics, maternities and dispensaries using handheld Global Positioning Systems (GPS) and satellite imageries provided by Google Maps ${ }^{T M}$. Additional information comes from questionnaires issued to the facility management and that serves as attribute data for both the database and visual map. Both attribute and spatial data are linked in AutoCad and ArcGIS environments to allow querying of information. Results show that 12 health facilities exist, of which 10 are public and 2 are private. Although the facilities are fairly distributed, their standards differ and that ignores the pattern of distribution. We hereby used the population data of 1993 and 2006 and the World Health Organisation (WHO) criterion for location of new health facilities in developing countries to propose 2 new sites. It is suggested here that, only if the standards are improved and the proposed ones built that Yola town can have adequate health facilities to the standard of WHO. The database produced would undoubtedly assist in management, planning and fostering new directions to health administration. The visual map produced shows locations of health facilities, road linkages and capacity of each is also an important source of information on health matters. The visual map if provided to the public can reduce the risk of taking patients to wrong hospitals due to not having prior knowledge of their capacities or opening hours. The satellite and information technology therefore can provide ease in management of health facilities and planning for future.
\end{abstract}

Keywords: Database, GIS, GPS, Mapping, Query

\section{INTRODUCTION}

Digital mapping has now become an indispensable tool in solving many environmental-based problems. The method used for producing digital maps is dependent on the level of details required, the use to which the map will be put into and the sourced data. Digital mapping operations help organizations achieve significant analytical and operational advantage. Location intelligence is empowering even non-Geographic Information Systems (GIS) experts to gain advantage of using location to make more insightful everyday decisions.

The ability of GIS to manipulate data from specific geographic locations, and the ability to gather, store, manipulate, analyse and visualize georeferenced data offers the opportunity to create a realistic perspective of the world and a chance to see the future action (Burrough, 2001). This unique ability provides scientist, engineers, surveyors, planners and resource managers the opportunity to distil and combine large sets of spatial data into useful information offering new perspective and fresh approaches to problem solving. The GIS is used in almost every facet of our daily lives, from earth science and other physical sciences to finance and management. Therefore, the data it uses also vary, ranging from remote sensing, Global Positioning Systems (GPS), conventional data collected by in situ instruments and questionnaires etc. These data that are either timeseries or spatial can be used to show spatial context of various fields and the creation of models and predictions of future occurrences.

Geospatial analysis and environmental health began to interact with each other due to advances in computing. The usefulness of this is in the ability to view maps and identify areas of prevalent diseases, pest breeding grounds, spatial population distribution for health studies, doctor-to-patient ratio and location of health facilities. For hazards ranging from soil lead, to particulates in the air, to disease carrying mosquitoes, researchers have used geospatial analysis to investigate where hazards exist in the environment and to model their spatial distributions (Glass et al., 1995; Guthe et al., 1992).

Early GIS applications in environmental health include analysis of spatial clustering of childhood leukemia in relation to nuclear facilities in England (Openshaw et al., 1988), a study that laid the groundwork for the extensive body of research on GIS-based analysis of spatial disease clusters. Other early studies include McMaster's (1988) GIS assessment of community vulnerability to hazardous materials and Wartenberg (1992) and Wartenberg et al. (1993) use of GIS to characterize populations living near high-voltage transmission lines.

The geospatial analysis tool, the GIS has been used in vector-borne disease studies to determine the associations between environmental features and vector concentrations (e.g. Glass et al., 1994). From much 
recent studies, GIS was used to map out vector-borne and zoonotic diseases such as Lyme disease, viral meningitis, hantavirus, Dengue Fever, Yellow Fever, and rabies, among others, and their spatial distribution. Ghosh (2011) used GIS to analyse the association of urban environment features that facilitated viral activities of West Nile Virus (WNV) and compared the spatial association between WNV infected mosquito pools and human cases with heterogeneous urban characteristics in Minnesota USA between 2002 and 2007. His results showed that WNV is considerable higher in areas close to swamps, parks and water discharge sites.

Donguset al. (2011) optimised the accuracy of the applications of larvicides at mosquito breeding sites in Dar-es-Salam Tanzania using GIS. They employed community-based development of sketch maps of the target areas that is termed participatory GIS and then involved a procedure of verifying the sketched maps using laminated aerial photographs in the field that are later analysed and digitised in a GIS system. The level of details obtained aided the government not only in malaria monitoring but in the implementation of council programmes and in spatially explicit analysis for research and evaluation purposes.

GIS has also been applied to depict mobile hazards associated with, for example, traffic flows and transportation of hazardous wastes (Lovett et al., 2006). Advances in geospatial technologies and space-time methods have greatly enhanced our ability to model and monitor the spatial distributions and flows of environmental hazards. Geospatial techniques have also been used to identify at-risk population (maps) exposed to radioactive iodine and lead poisoning (Wartenberg, 1992; CDC, 1997).

There are three important functions of Geographical Information System (GIS) in health research and policy analysis: spatial database management, visualization and mapping, and spatial analysis (Cromley and McLafferty, 2002).

WHO (1997) specified criteria for health care planning for third world countries and indicated that each service area should cover $4 \mathrm{~km}^{2}$ catchment area with a population of 60,000 for primary health care in order to have adequate and equity of access to health centres. In line with WHO (1997), this study therefore aimed to map the spatial distribution of health care centres in Yola Town of Adamawa State using GIS techniques. This aim will be achieved by identifying, mapping, and creating a GIS database for public and private health centres in the study area.

The provision of health care centres in Nigeria is a concurrent responsibility of the three tiers of government that include Local, State and the Federal Government institutions. The local government is the smallest administrative unit. In addition to this, private investors in healthcare delivery are also visible. The Primary HealthCare (PHC) Department is one of the five departments of each of the 774 local government councils in the country that is charged with the responsibility of ensuring that healthcare services are delivered in their own domains on an integrated and affordable basis. Location mapping, however is critical in reaching out to the people within their respective areas of jurisdiction.

The ability to locate health facilities and identify their capabilities in terms of services and hours of operation has been underscored due to lack of proper mapping facilities. Unlike in the developed world where all health facilities are of equal standard, in the developing world it is different. Therefore, those needing medical help would be wondering as to which facility to visit? Do the chosen health facility operate 24 hours? Do they have pharmacy? Do they have beds? At some instances, laboratories are also required for the purpose of blood transfusion and examination of pathogens. The first objective of this paper is to provide the ability to check these information on a computer, either online or not to achieve even more details on health facilities. These can be queried and results generated in no time. The second objective is to provide these information on a single visual map.

Abbas et al. (2012) investigated the spatial distribution of Healthcare facilities in Chikun local government area of Kaduna State Nigeria by employing GIS and GPS to map exiting ones, evaluate adequacy based on World Health Organisation standard and propose new ones. However, their results neither show how queries could be made to show both spatial and attribute information from a database, nor provide a visual map portraying details of health facilities. Here, we provide a spatial database management for querying and retrieving information on health matters, and a single visual map of the health facilities and analysis of provisions in each facility.

The study area is Yola Town, the Head Quarters of Yola South Local Government Area. It is a twin town with Jimeta that is the capital city of Adamawa State, Nigeria. It lies between latitude $\left[09^{0} 11^{\prime} 31^{\prime \prime} \mathrm{N}\right.$ and $\left.09^{0} 13^{\prime} 10^{\prime \prime} \mathrm{N}\right]$, and longitude $\left[12^{0} 27^{\prime} 32^{\prime \prime} \mathrm{E}\right.$ and $\left.12^{0} 31^{\prime} 13^{\prime \prime} \mathrm{E}\right]$ of Greenwich meridian. 


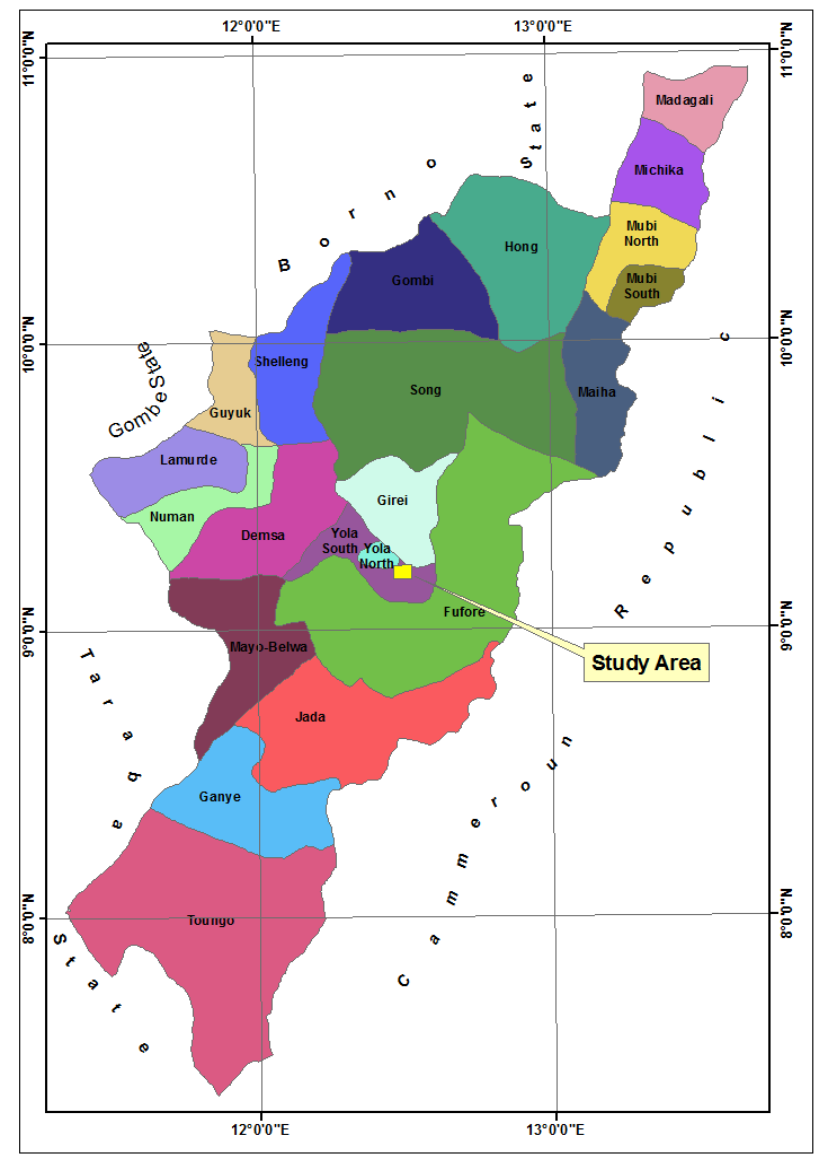

Figure 1: Map of Adamawa State showing Yola South Local Government Area. The yellow box indicate location of the study area.

\section{Methodology}

Materials and equipment used are satellite map of Yola Town obtained from GoogleMaps ${ }^{\mathrm{TM}}$, a handheld Garmin 60 GPS, AutoCad 2010, ArcGIS 9.3 software and questionnaires enquiring on each health facility.

The Yola map obtained from Google Maps ${ }^{\mathrm{TM}}$ was used as a basemap. However, it was not detailed, updated or conform to actual street names on the ground. A procedure of Musa (2005) was employed to update the map, first by correcting the naming of major roads and then incorporating various minor and access roads that do not exist on the Google Map. This was achieved by site visit to ground-truth existing street map.

To obtain necessary information about the health facilities, we issued questionnaires to each of them. The information we require include name of health facility, ward location, category e.g. hospital, clinic, dispensary, maternity etc. Others include ownership e.g. government or private, number of patients per day, opening hours, number of doctors/nurses, laboratories, pharmacies, number of beds etc.

The coordinates of each health facility were obtained using the GPS. These were georeferenced on the Google satellite image using AutoCad software. On screen digitization was done using ArcGIS 9.3. This was to produce features such as roads digitized as lines and Health Facilities and roundabouts as polygons. The spatial data were organized in layers, and the ability to query was made possible using the query builder in ArcGIS. A few of the queries performed were: 1) How many private health facilities are located in Yola Town? 2) How many public health facilities are located in Yola Town? 3) Do all of the health facilities have doctors and nurses? 4) Where can new health centres be located?

To produce a Health Facility single visual single map containing all information that could be required by persons needing to visit a health facility, we used the updated street map with locations of health facilities and the information retrieved from the questionnaires. 


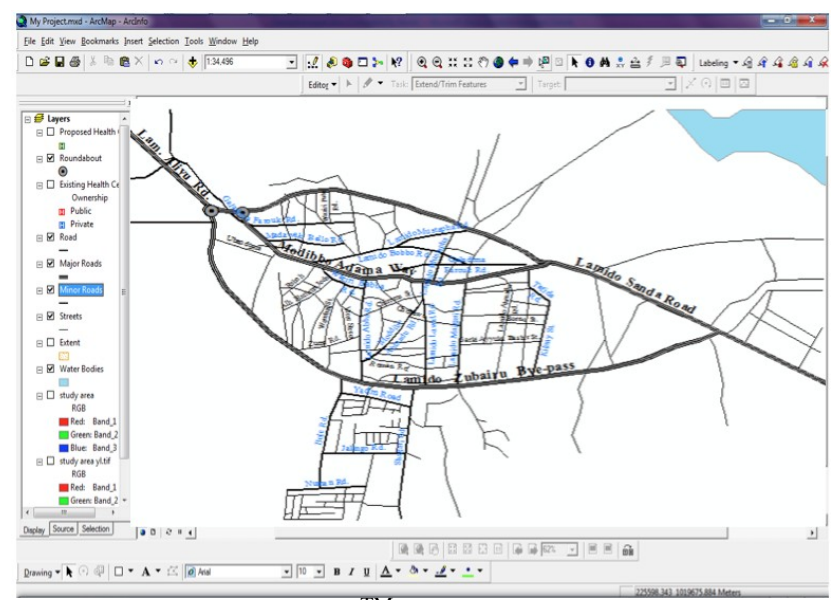

Figure 2: Existing street naming on Google Maps ${ }^{\mathrm{TM}}$ are in black. Ubdated street names in blue and unnamed streets as plain black lines. To the top-right corner is Njuwa Lake.

\section{Results and Discussions}

With the start of this mapping procedure, some adaptations were made to the approach. The satellite imageries provided by Google Maps ${ }^{\mathrm{TM}}$ do not show all the road networks and some street namings are incorrect. However, the imageries are still useful considering their high resolutions. We therefore use them as basemaps and updated the streets and corrected the wrongly named ones (figure 2 ). The originally correct namings are in black, new ones in blue and streets that do not have names are represented as simple black lines.

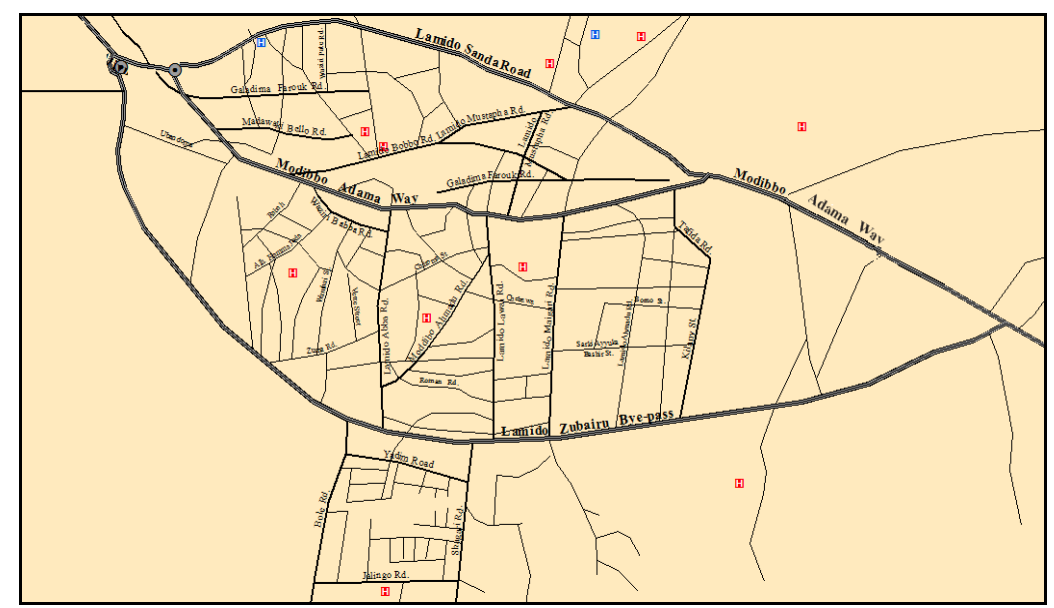

Figure 3: The spatial distribution of the health facilities in Yola Town. Red and blue squares represent government and private health facilities respectively. Minor and access roads that links these facilities are shown in thick and light lines respectively.

Table 1: Query of attribute table showing public healthcare facilities in yellow.

\begin{tabular}{|c|c|c|c|c|c|c|c|c|c|c|c|c|c|c|c|c|}
\hline \multicolumn{7}{|c|}{ 圈 Attributes of Existing Heath Centers } & \multirow[b]{2}{*}{ ADDRESS } & \multirow[b]{2}{*}{ DOCTORS } & \multirow[b]{2}{*}{ NO_OF_DOCT } & \multirow[b]{2}{*}{\begin{tabular}{|l|} 
NURSES \\
\end{tabular}} & \multirow[b]{2}{*}{ HO_OF_NUR } & \multirow[b]{2}{*}{ LAB } & \multirow[b]{2}{*}{ BEDS } & \multicolumn{3}{|c|}{\begin{tabular}{l|l|l|}
$\square$ & $\mathrm{X}$ \\
\end{tabular}} \\
\hline $\mathrm{FID}$ & Shape & 105 & S-No & NAME & LON & LAT & & & & & & & & PHARMACY & HRS_OF_OPE & \\
\hline 0 & Point & 2 & 1 & Adamawa Hospital & 222197 & 1019382 & Mkakama B & YES & 5 & YES & $8^{8}$ & YES & & YES & & Private \\
\hline & Point & 3 & 21 & Nana Asma'u Mlaternal And Child Clinic & 222789 & 1018901 & Makama B & YES & 2 & YES & 5 & YES & & YES & 24 & 4 Public \\
\hline & Point & 4 & 3 & Yol Central Dispensary & 222805 & 1018825 & Makarana B & NO & NLLL & NO & NILL & NO & & NO & 24 & 4 Public \\
\hline & Point & 5 & $4 \pi$ & Toungo Heath Clinic & 223511.704 & 1018027.009 & Toungo ward & NO & NILL & NO & NILL & NO & & YES & 24 & 4 Public \\
\hline & Point & 6 & 51 & Wuro Hausa Heath Clinic & 224634 & 1018791 & Adarawo & No & NILL & YES & 13 & NO & & NO & 24 & 4 Public \\
\hline & Point & 8 & 7 F & FuCYola & 22489.2871 & 1017553.774 & Bole Yolde Pate & YES & 20 & YES & 100 & YES & 150 & YES & 24 & 4 Public \\
\hline & Point & 9 & 8 & Adniral. H. M. NyakoShagari & 222972 & 1016798 & Bole Yolde Pate & YES & 1 & YES & 8 & YES & & YES & 24 & 4 Public \\
\hline & Point & 10 & 91 & Toungo Nursing \& Maternity & 223862 & 1019502 & Makarara $A$ & YES & 2 & YES & 8 & YES & & YES & 24 & 4 Private \\
\hline & Point & 11 & 10 & Pob Damare Clinic & 224100 & 1019494 & Makarara A & NO & NILL & YES & 6 & YES & & NO & & 4 Public \\
\hline & Point & 12 & $11 \mathrm{~L}$ & LanidoAliyu Mustapha Heath Clinic & 223634.369 & 1019359.95 & Makarara A & YEA & 1 & NO & NILL & YES & & YES & & 4 Public \\
\hline 10 & Point & 13 & & Yode Pate Health Clinic & 218513 & 1019003 & Bole Yolde Pate & NO & NILL & YES & 1 & NO & & YES & & 2 Public \\
\hline 11 & Point & 14 & 13 & Bato Heath Clinic & 222326.6 & 1018336 & Bako Ward & NO & NILL & YES & 3 & YES & & YES & & 4 Public \\
\hline & Point & 15 & 14 & Balarillbamoi Heath Clinic & 223009 & 101815 & Mbamoi Ward & NO & NLLL & NO & NILL & NO & & YES & & 2 Public \\
\hline & & & & & III & & & & & $\square$ & & & & & & 1 \\
\hline & ecord: 14 & & 1 & "II Show: $\sqrt{\text { All }}$ Selected & Records (11 out of 13 Selecte & & Options - & & & & & & & & & \\
\hline
\end{tabular}


The existing health facilities are shown in figure 3. Two facilities are privately owned. These were georefenced over the updated road map. Red and blue squares represent government and private health facilities respectively. Minor and access roads that links these facilities are shown in thick and light lines respectively. The many road networks in the town show ease of access to health centres. There were more public health facilities $11(84.6 \%)$ than private health facilities $2(15.4 \%)$. The two privately own facilities are skewedly located to the north and one even in between two public facilities. The database query using attribute table (table 1) shows the names of the public and privately owned facilities. It is also possible to query the database spatially. In this case, the spatial map is generated showing locations of facilities and highlighting what was queried. For example, a health facility such as Lamido Aliyu Mustapha Health Clinic can be queried using the HTML popup in ArcGIS as shown in figure 4. Detailed information about the facility contained in the database is shown in a popup table to left of the figure, while an indicator arrow shows the spatial position.

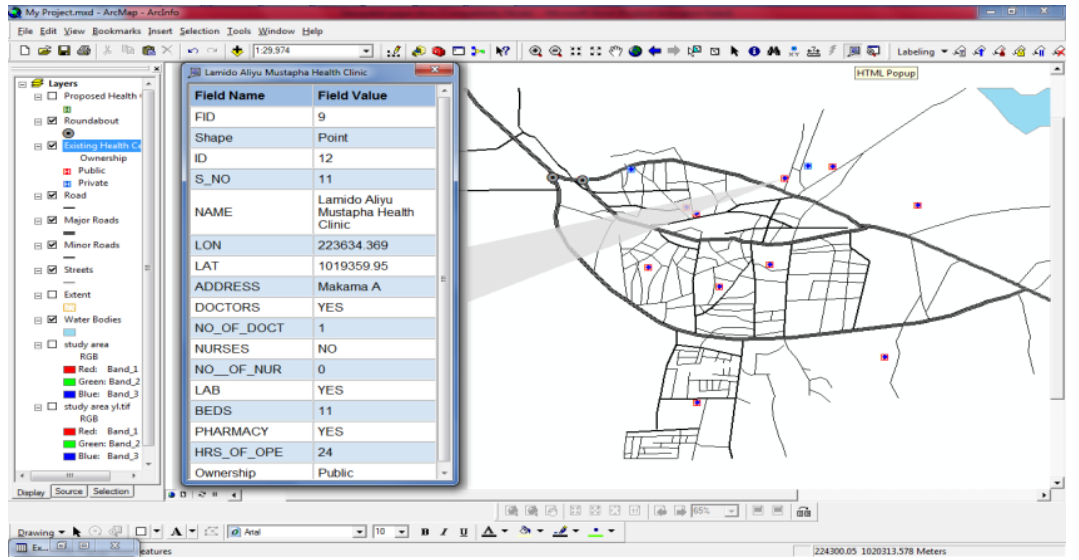

Figure 4: Identifying a health facility using HTML Popup. The popup table to the left shows all information about the facility contained in the database.

\subsection{Proposing New Health Facilities}

Having analyzed the existing health institutions in Yola, it would also be worthwhile assessing the need of establishing others to equip the town with the growing population. The population of each ward is increasing due to the rural-urban migration that has been on the increase in recent years. Therefore, existing facilities won't go round for all, and the necessity of establishing others is essential. Although, proximity of the existing facilities to the users and access to road and water has satisfied the criteria of WHO (World Health Organisation), population is not. The WHO (1997) set out a criterion for siting health facilities based on population. An area with a population of 500 people should have access to at least 1 health centre with the main equipment. Although there are 7 facilities equip to the standard required (see table 1), population-wise the town is still below average. For example, the population of each ward has grown dramatically between 1993 and 2006 (figure 5). Considering this population increase, we suggest additional facilities be made. However, our proposition here has considered areas with higher population such as Bole-Yolde Pate and WuroChekke (a part of Wuro Hausa ward) that has grown dramatically not only during the 1993-2006 period but after 2006. Significant population increase due to new settlements has been observed in these areas recently compared to other parts of the town.

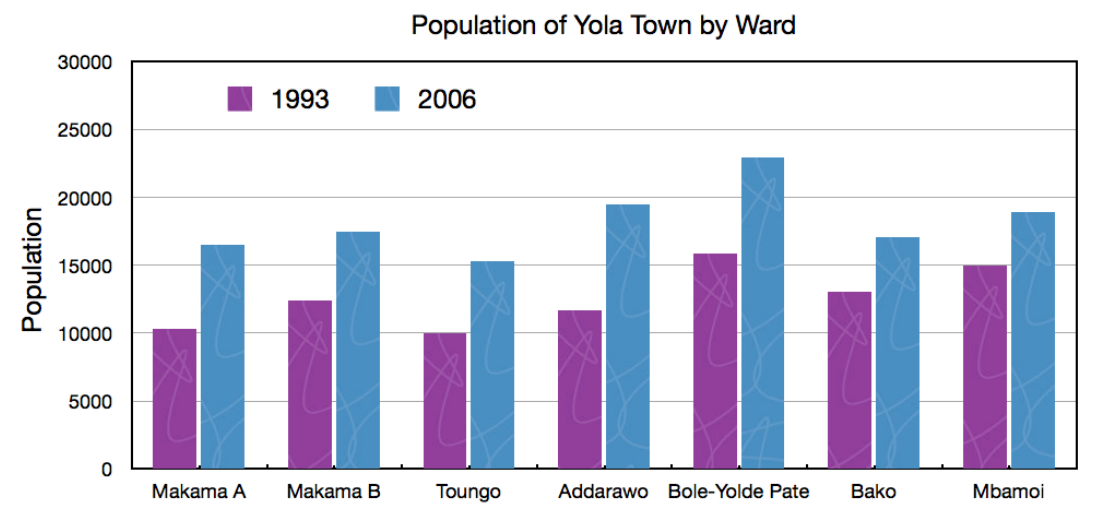

Figure 5: Population of wards in 1993 and 2006 in Yola Town. Data sourced from National Population Commission, Yola. 
The proposed health facilities are shown in figure 6. To the northeast lies WuroChekke, a part of Wuro Hausa Ward, and to the southwest, a new layout that is a part of Bole - Yolde Pate. The final map of existing and proposed health facilities are shown in figure 7. The existing facilities are in red (public) and blue (private) while the proposed are in green. The final map is also query-generated.

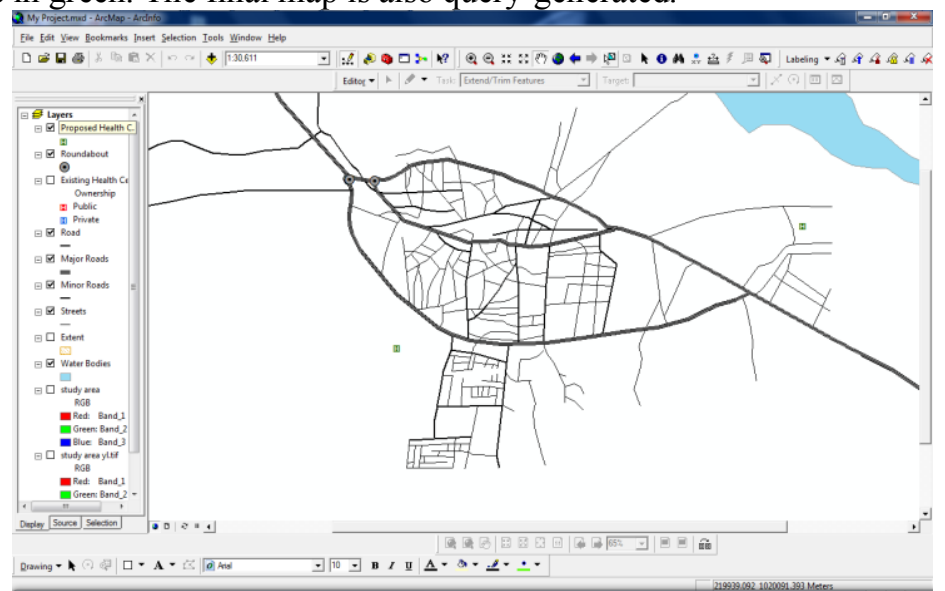

Figure 6: Proposed health facilities based on criteria set by World HealthOrganization (WHO) in 1997.

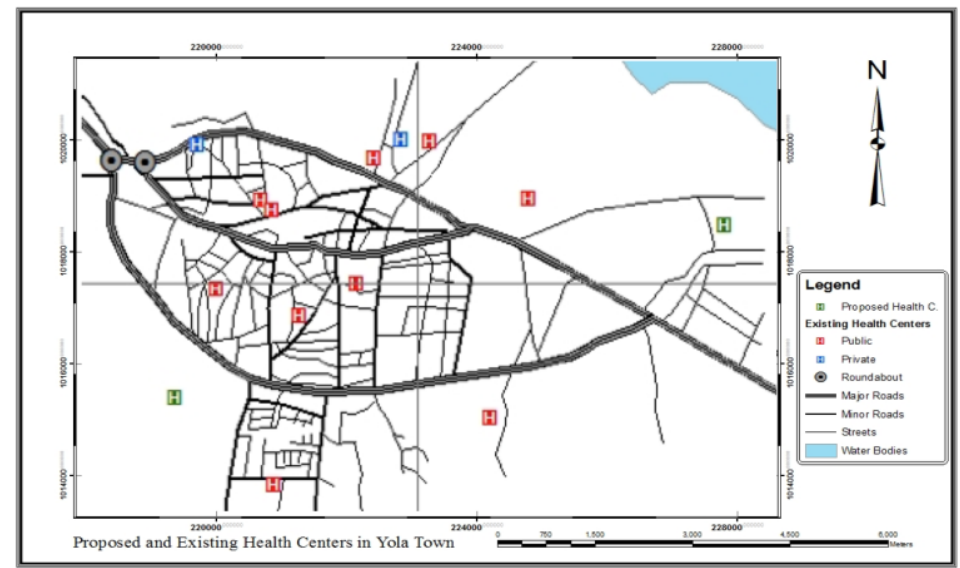

Figure 7: Map of Yola Town Showing all the Proposed and Existing Healthcare Facilities. Existing are red (public) and blue (private) and proposed (Green).

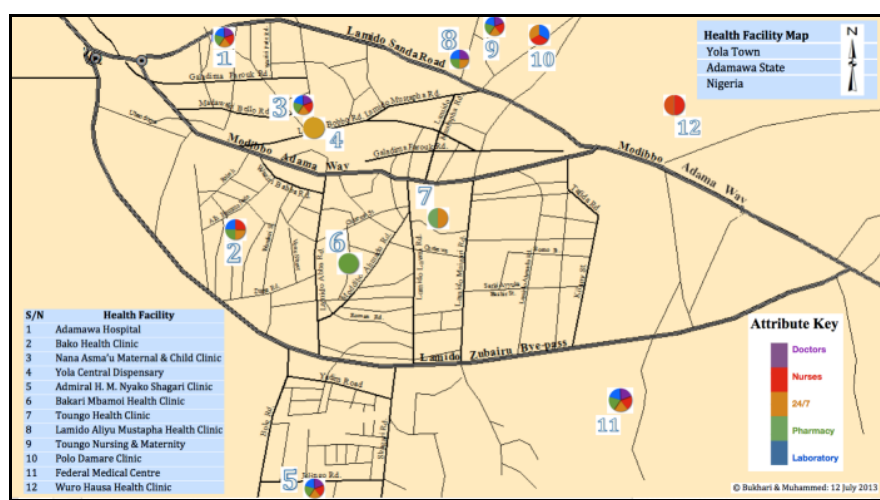

Figure 8: Visual Health Facility Map of Yola. Each facility is numbered and named and their attributes are show in color.

\subsection{Visual Health Facility Map}

Visual map of the health facilities and analysis of provisions in each facility are shown in figure 8 . The map shows locations of facilities and their names and attribute information at a go. With this map, it becomes easy for any one needing to visit a health facility to glance and know which one to go to. Additional information to be obtained instantly are road access, availability of doctors/nurses and other provisions such as pharmacy, laboratory and service hours. These attribute information are in colour and identified by a key. 


\section{Summary and Conclusion}

This paper is aimed at creating a database of health facilities in Yola Town and producing a visual map that can provide all information at a go. The procedures adopted involved the use of state-of-the-art technology in mapping these facilities. The Global Positioning System has been used to obtain the coordinates using a handheld Garmin 60 instrument, while processing involved the use of two different software packages, the ArcGIS 9.3 and the AutoCad 2010. The attribute information were obtained as the outcome of questionnaires served, and these are necessary for database creation and in the production of the visual map. Using information on existing health facilities, WHO criterion on establishment of health facilities and the population data, two new ones are proposed. Results show that the town has in total 97 doctors, 252 nurses, one facility operating at 12 hours rather than 24. In addition, 4 out of 12 has no laboratory, and two has no pharmacy. Although this data may rather appear great, we suggest here that only if we could standardize all health facilities and establish the new ones, we could not attend the standard laid down by the WHO.

This research can be used for a variety of applications that include health research and interventions, identifying areas that needed to be improved, vaccination programmes, waste management programmes, town planning and location of new facilities. It could also assist government administrators in the distribution of health personnel and medical facilities. In addition, visitors can locate health facilities easily, while residents can locate facilities that provide some particular needs at any point in time. In general, it can be used for spatially explicit analysis for research and evaluation purposes. The visual map, for example can be provided to one-stopshops, tourist information centres as well as heritage and museums alike.

\section{Acknowledgement}

The authors are grateful to the management and staff of health facilities in Yola Town, Adamawa State, Nigeria and to the anonymous reviewers for taking their time to improve this article.

\section{References}

[1] Abbas, I.I., Auta, S. Z., and Muhammad, R. (2012). Health Care Facilities Mapping and Database Creation Using GIS in Chikun Local Government, Kaduna State, Nigeria. Global Journal of Human, Social Science, Geography \& Environmental GeoSciences. Vol 12, Issue 10, No 1.

[2] Burrough, P. (2001). Principles of Geographic Information Systems Spatial Information Systems and Geo-informatics. New York; Oxford University Press PP.20.

[3] CDC, C. f. D. C. a. P (1997) Screening young children for lead poisoning: Guidence for state and local public health officials, Atlanta, GA.

[4] Cromley, E.K., McLafferty, S., (2002). GIS and public health.New York: Guilford Press.

[5] Dongus, S., Mwakalinga, V., Kannady,K., Tanner, M. and Killeen, G. (2001) Participatory Mapping as a Component of Operational Malaria Vector Control in Tanzania. In Geospatial Analysis of Environmental Health, Geotechnologies and the Environment 4, DOI 10.1007/978-94-007-0329-2 16.

[6] Ghosh, D. (2001) Participatory Mapping as a Component of Operational Malaria Vector Control in Tanzania.In Geospatial Analysis of Environmental Health, Geotechnologies and the Environment 4, DOI 10.1007/978-94-007-0329-2 7.

[7] Glass, G., Amerasinghe, F., Morgan, J., Scott, T. (1994) Predicting Ioxdesscapularis abundance on white-tailed deer using geographic information systems. Am J Trop Med Hyg 51(5): 538-544

[8] Glass, G., Schwartz, B., Morgan, J., Johnson, D., Noy, P., Israel, E. (1995) Environmental risk factors for Lyme disease identified with GIS. Am J Public Health 85(7):944-948

[9] Guthe, W., Tucker, R., Murphy, E., England, R., Stevenson, E., Luckhardt, J. (1992) Reassessment of lead exposure in New Jersey using GIS. Environ Res 59(2): 318-325

[10] Lovett, A., Parfitt, J., Brainard, J. (2006) Using GIS in risk analysis: a case study of hazardous waste transport. Risk Anal 17(5):625-633

[11] McMaster, R. (1988) Modeling community vulnerability to hazardous materials using geographic information systems. In: Proceedings, third international symposium on spatial data handling. Sydney, pp 143-156

[12] Musa, A.A. (2012). The Application of Satellite Images, GPS and GIS in Revising TownshipMap - A case study of Jimeta - Yola, Adamawa State. Nigerian Journal of Surveying and Geoinformatics, Nigerian Institution of Surveyors.

[13] Openshaw, S., Charlton, M., Craft, A. (1988) Searching for leukemia clusters using a geographical analysis machine. Pap RegSciAssoc 64:95-106

[14] Wartenberg, D. (1992) Screening for lead exposure using geographic informaiton system. Environ Res 59:310-317

[15] Wartenberg, D., Greenberg, M., Lathrop, R. (1993) Identification and characterization of populations living near high-voltage transmission lines: a pilot study. Environ Health Perspect 101(7): 626-631

[16] World Health Organization (1997) Geographic Information Systems and Public Health Mapping.http://www.who.int Accessed on 15 October 2013 